\title{
A Proactive Model to Control Reactive Behaviors
}

\author{
Vida Dehnad ${ }^{1, *}$ \\ ${ }^{1}$ Lecturer, English Department, University of Neyshabur, Iran \\ *Correspondence: English Department, University of Neyshabur, Khorasan-e Razavi, Iran. Tel: 98-514-330-5000. \\ E-mail: vida_dehnad@yahoo.com
}

Received: July 3, 2017

doi:10.5430/wje.v7n4p24
Accepted: July 27, 2017 Online Published: August 6, 2017

URL: https://doi.org/10.5430/wje.v7n4p24

\begin{abstract}
Adaptation to change is not an easy process and sometimes does not happen at all. When people perceive that their freedom is going to be altered due to an unwanted change, they outwardly exhibit some symptomatic reactive behaviors such as inertia, resistance, skepticism, and aggression. No matter how intense people's reactance is, only a few of them may manage to examine the unwanted change more deeply and find a way to conform or adapt. Knowing this, the current article focuses on a theoretical proactive model or a solution. The model mainly works on the idea of recognizing the symptomatic behavioral reactance of learners. In other words, in the face of the reactance-induced behaviors depicted in the model, the instructors can apply four proactive strategies of brainstorming, open transparent conversation, small scale project assignment and triple "c" rule by means of which they can walk learners safely towards mutual trust, classroom stability and learner commitment. In the end, as the model is new, there is still enough room for further experimental researches on different aspects of the model in actual classroom settings.
\end{abstract}

Keywords: proactance; reactance; proactive model; inertia; resistance

\section{Introduction}

"When a situation immediately creates fear, anxiety or distress, the logic of action becomes emotional" (Bourion, 2005, p.39). Accordingly, when an individual is involved in an unknown situation, it will be gravely important for him to maintain his emotional and cognitive equilibrium. Gentry (2016) believes that individuals develop varying degrees of tolerance in new situations since they have different personality traits. In other words, every person develops his own unique view of changes that happen around him on a regular daily basis.

Now as a research topic, it can be quite interesting to explore more about the potential experiences individuals may go through while facing changes. One good starting point can be educational contexts. In these contexts, challenges are usually parts of the learners' lives and act as stressors leaving significant influences on their behavioral and cognitive responses (Miner, Schueller, Lattie \& Mohr, 2015). Some of these responses may aggravate the learners' academic standing while some tend to improve it.

The present article is not an experimental research. It is rather explanatory in design. Thorough the article, the current researcher provides concise functional explanations about the main types of reactions that students usually develop and offers a proactive model that teachers can apply in such situations. After all, knowing about students' reactions will be of facilitative nature in classroom management.

On the other hand, knowing about proactive strategies is of equal importance to teachers since they are always expected to work harmoniously with their students, to understand them, and to help in maximizing the total output of their classroom interactions. Indeed, such give and take mechanisms are staples of healthy educational systems. It is understandable that when teachers are not accountable or well aware of students' challenges, most often, the stressors in such settings will lead to students' unsatisfactory rate of progress and accordingly their cognitive inefficiency. The latter state is associated to the students' inability to process new information optimally (Hidary, 2015). 


\section{Review of Related Concepts}

\subsection{The Elizabeth Ross's Idea of Reactive Change Curve}

Our everyday interactive experiences with people in particular and with social institutions in general can affect our value systems and beliefs (Kinder, 1987/2016). These interactions constitute our unique sense of self and our strategic social approach towards changes. We also have different degrees of adaptability to the sudden changes we perceive as undesirable. In other words, our flexibility qualities or "adaptive manners" are species-wide mechanisms that can result in various types of learning and reactions (Wright, Eberhard, Hobson, Avery \& Russello, 2010, p.393). However, the movement towards adaptation is never an easy process for some people and depending on the situation, people's journey towards adaptability would differ. In grave situations with threatening nature, according to Kubler Ross (1969) who counseled near-death patients, people usually go through five reactive stages of denial, anger, bargaining, depression, and finally acceptance or decathexis. These cyclical stages before adaptation may not be observed in exactly the same manner in everyone's journey since some people may stop at a stage and never move on (Chapman, 2006/2013). However, the significance of the cyclical changes brought forth by Ross lies in the fact that Ross depicted a universal change curve that is realized with various intensities in different individuals.

Besides clinical settings, the change curve has been growingly applied to business and management situations where any detailed analysis of reactive behaviors can help business owners or managers with greater future efficacy and more positive yields (Portier, 2016). Pay attention to the diagram below that is an adaptation of Ross' change curve, in which a person starts with denial and goes through an exploration phase before his/her final commitment to an unwanted situation. The diagram also shows that the pressures of changes are first external and then internal before arriving at inner resolutions.

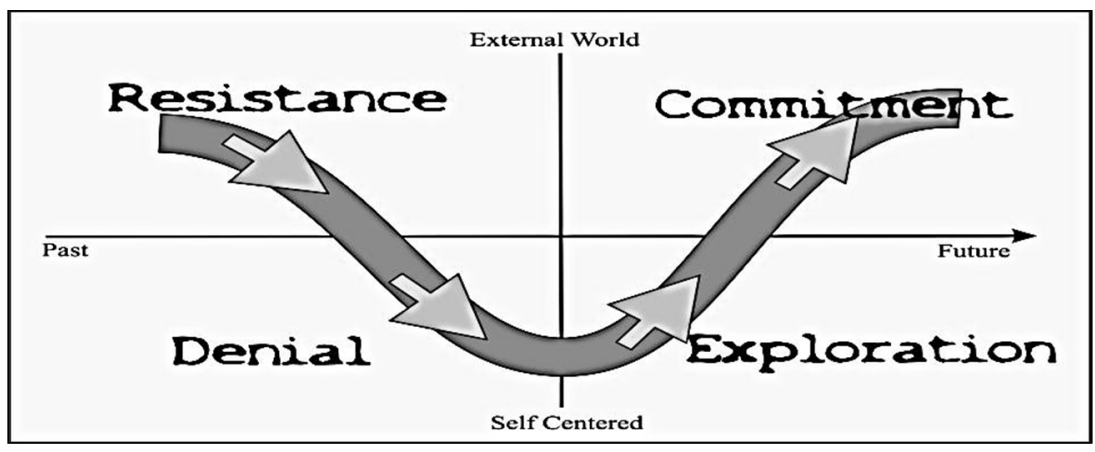

Figure 1. The Change Curve(Note 1)

\subsection{Four Types of Reactance}

As early as 1966, a related, but still a different concept of change was introduced by Jack Brehm. He called this concept the psychological reactance. His theory of psychological reactance also deals with the idea of how a threat to someone's most valuable freedom makes him reactive to the perceived change. Again, as earlier mentioned, the intensity of reactions to threatening changes is different from person to person. In other words, as Dowd, Wallbrown, Sanders, and Yesenosky (1994) have indicated, when individuals' reactive behaviors are studied, their personality differences can be of help in interpreting the intensity of their reactions. For instance, those who prefer to be autonomous and to deny others' control tend to manifest more severe type of reactance as a response to threatening factors.

Moss (2016) also believes that reactance can be sometimes triggered by the messages people perceive as domineering or high-handed. Citing Quick and Stephenson (2008), Moss associates such written or oral messages to undesirable thoughts of restriction or control. He has also classified some linguistic features that can be reactance arousing:

- Obligation modalities including must, should, have to

- Absolute assertions including "no one can disagree that"...etc.

- Vilifying statements about others' opinions including "no rational person would do this"...etc.

○ Direct warnings including "I will give a failing grade to you"...etc. 
In some researches, reactance has been equated with boomerang effect (Brehm \&Brehm, 1981) appearing as an involuntary behavior with four outward symptomatic faces such as inertia, resistance, skepticism, and aggression in varying degrees (Fox, 2011; Moss, 2016). Regarding the notion of reactance-induced behaviors, Kuppens, Allen, and Sheeber (2010) define psychological inertia as an effect of emotional maladjustment and cognitive unresponsivity to changes. In other words, not always a sudden unwanted change is met with severe reactions such as aggression or explicit repulsivity. In some rather intense situations, when an individual's response to changes decreases noticeably, he comes over a passive psychological state called inertia (Bylsma, Morris, and Rottenberg, 2008).

According to Jost (2015), psychological resistance in the sense of not wanting to conform or cooperate is greatly related to people's attachment to their views about themselves or the world. That is to say, whenever a change targets individuals' belief systems, they may develop resistance, denial and untrust towards the agents of change. The diagram below explains some of the appearances of psychological reactance as discussed:

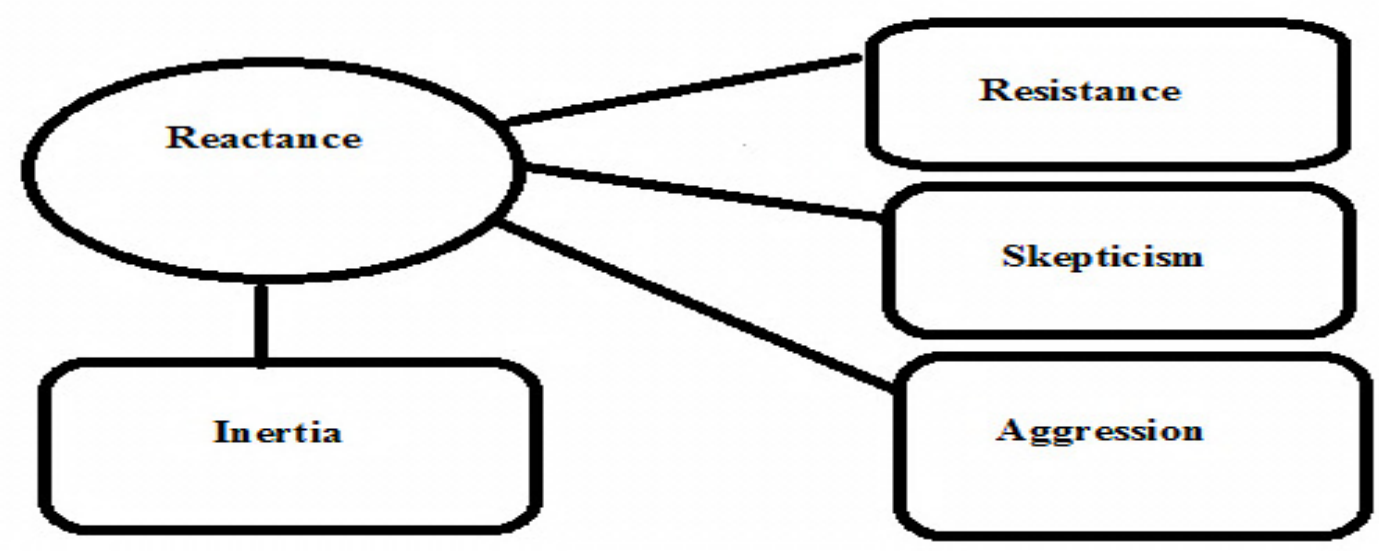

Figure 2. Different Faces of Reactance in Different Situations(Note 2)

\subsection{Proactance}

In spite of the difficulty of overcoming reactance, according to Zhang and Sapp (2012), teachers' closer interactions with students and less domineering requests may alleviate the outward appearances of psychological reactance in educational settings. In fact, the alleviation procedures are some proactive strategies that can counter reactance and help learners to demonstrate the optimal behavior of commitment quite faster. Putting it generally, both teachers and students can handle their interactants' reactive behaviors by predicting the possible outcomes of changes. These future-oriented adapting behaviors are known as proactive strategies (Grant and Ashford, 2008). Proactive behaviors are thus characterized by individuals' decision-making for future, predicting future outcomes, adopting solution strategies and exploring all possible ways to win over undesirable situations (Parker and Collins, 2010). Thus, proactance on the part of instructors can neutralize students' reactance.

The term proactance, of course, has not been much used in the literature of change and there are just a few instances of use for it. Allen (2006), for example, has applied the term to refer to a psychological state in which a student facing a challenging situation such as racial discrimination is emotionally stirred to control it in a positive way. The term, as he indicates, leads to positive outcomes.

As proactance can cope with individuals' disruptive behaviors, in most organizations, educational settings and institutions, it is usually considered as indicative of progress (Mazurkiewicz, 2015). According to Clunies - Ross, Little, and Kienhuis (2008), proactance on the part of instructors is move towards amending a situation that has aroused negative behaviors. Therefore, proactive strategies are both corrective and preventive. Pay attention to the figure below that sums up the characteristics of proactance: 


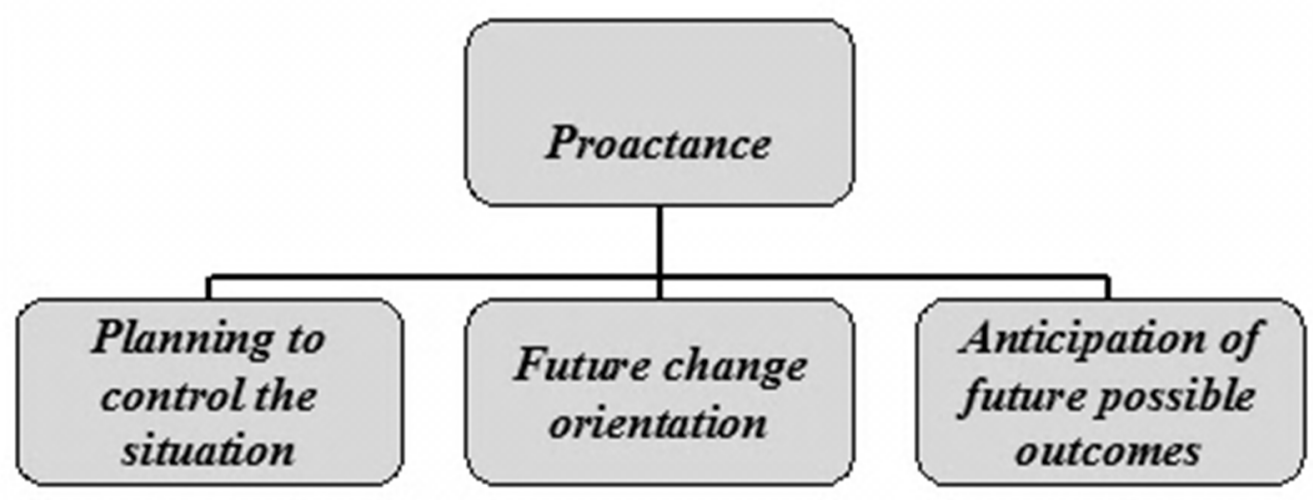

Figure 3. Characteristics of Proactance(Note 3)

\section{Discussion}

Entering universities and colleges usually offers a wide variety of opportunities and new experiences. However, changes in learning settings usually entail new expectations, rules, regulations, and chances of competition that are not easily tolerated by some students. Sometimes, students' various degrees of receptivity to change can lead to false judgments of their own competence, mistrust, and, at times, erroneous perceptions of teachers' biases. These, in turn, arouse all spectrums of troubles in educational environments. Hence, it is of utmost importance for instructors to manage their classrooms efficiently and to provide an environment where students develop mutual trust and responsibility towards their own learning objectives. The explanatory section below briefly touches upon a proactive model that can help teachers in reactance alleviation, proactance encouragement, and developing commitment.

\subsection{The Main Components of the Proactive Model}

The proactive model, as mentioned above, may not be new. Actually, it is a reformulation of the opinions of educational experts into a model that addresses the four appearances of reactance, namely inertia, resistance, skepticism, and aggression. Facing these four symptoms, an instructor who feels the toxicity of reactance in an academic environment can take four neutralizing strategies of brainstorming, transparent conversation, small project assignment, and triple "c" rule. Of course, the neutralization of reactance before it is embedded is quite important. In this regard, proactance can be equated with strategies that lead to trust and ease of communication between the parties involved. Pay attention to the reactive states and the components of the suggested model below:

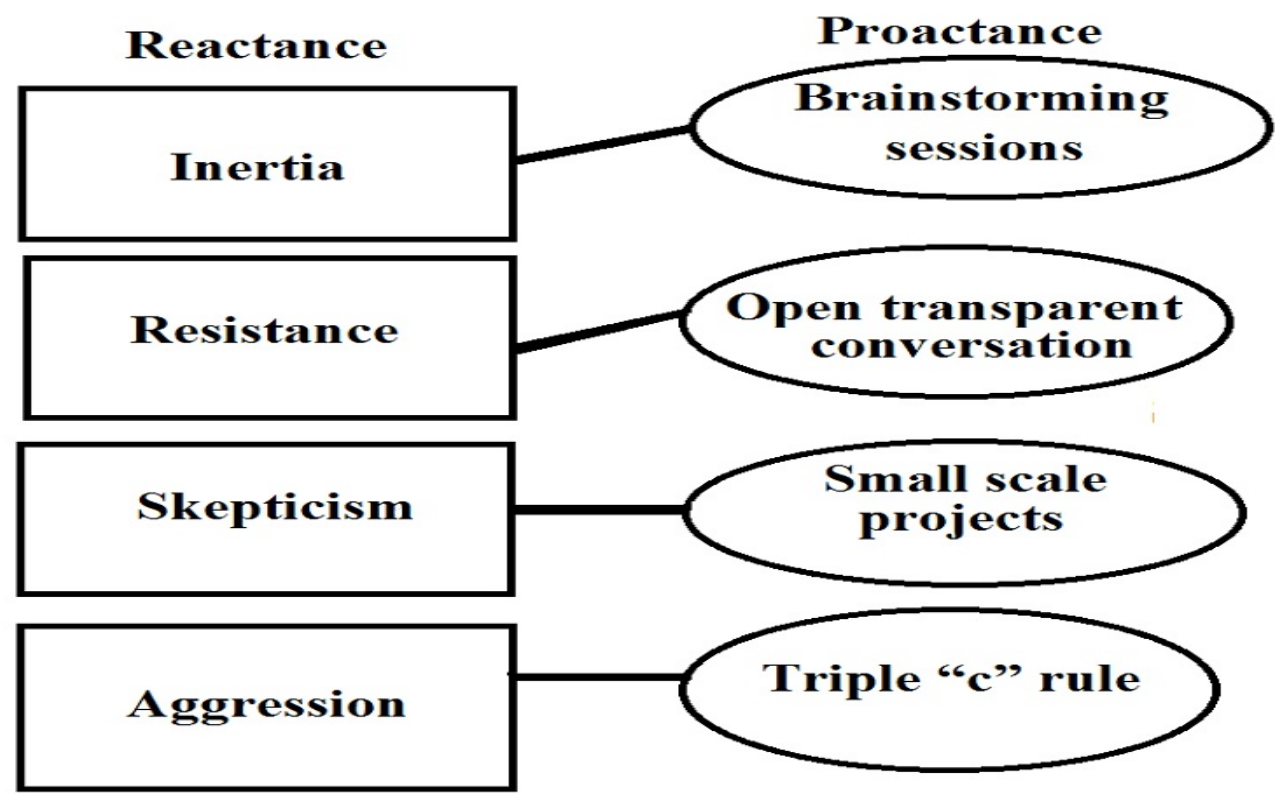

Figure 4. Proactive Model Components Developed by the Current Researcher 


\subsubsection{Brain Storming Startup Sessions}

Augmentation of students' cognitive function is one of the main goals of teaching. Nobody, in this regard, denies the positive influence of regular practices on students' cognitive abilities. According to Hohlbaum (2016, para.2), we get easily trapped by unresponsivity to change since we are "hardwired for inattention and inertia". However, if inertia is the result of undesirable changes rather than one's personal choice for slackness, there may be some methods, or deliberate strategies for overcoming it. One such strategy, as suggested by Sharp (2011) and Haine-Gadd (2016), is brainstorming. In brainstorming sessions that can be usually planned at the start of a study program, an instructor should encourage learners to talk freely about their expectations, imaginations, problems, fears, and goals. The instructor can then illustrate for learners a variety of situations that are likely to happen throughout their program. A learner should also be given enough awareness that changes are not always easy to tackle. In fact, unexpected changes can be quite overwhelming while imposing noticeable pressures on students' cognitive capacities. Brainstorming sessions thus serve as mental modeling programs. Davis and Arend (2013) mention several benefits of mental modeling practices that will be briefly listed in the following:

$\circ$ Better cognitive functioning

- Spotting the problem(s)

- Guided search for potential solutions (hows)

- Easing down on the fear of loss

It is good to mention that a great source of frustration for learners can be over-reliance on their own capabilities. The brainstorming sessions can thus positively assist students to embrace their own weaknesses by listening to their peers' self-disclosures about the weaknesses, the losses, the problems they also faced, and the solutions that were helpful to them.

\subsubsection{Open Transparent Conversation}

Sherman and Cohen (2006) believe that whenever people's sense of self-perfection is threatened by a cause, they resort to resistance by producing opposite arguments to maintain or restore their ideal unchallenged image. In case of resistance induced behaviors, Webster (2016) suggests conversation as an effective management technique. That is to say, instructors can initiate transparent discussions with those displaying resistance (Belcher, 2016; Rick, 2013). In a "dyadic interaction" or motivational interviewing, the parties are less likely to develop "confrontational" images of each other. Therefore, one of the direct benefits of open conversations is reducing stress and negativity in learners (Klonek, Güntner, Lehmann-Willenbrock \& Kauffeld, 2015).

\subsubsection{Small Scale Projects}

According to Reynolds (2015), the assignment of small-scale projects, in short run, can helpfully instill the thought of capability and attainment in learners. Hence, the instructors who wish to reduce learners' skepticism can safely apply this suggestible strategy. In other words, when a change is involved, learners may develop uneasy feelings of skepticism about themselves, their abilities to achieve, the authority of their instructors and etcetera. However, academic gains though small, can ease down the feeling of failure and self-doubt among learners.

The important point is that people's skepticism usually erupts out of an unresolved question about their inner conceptual makeup or the constitutive norms of the outside world that lead to "suspension of judgment" and harm to their "peace of mind" (Olfert, 2015, p.164). In this case, the sense of achievement has the tendency to remedy an individual's undesirable mental struggle and to end in peace and elimination of doubt.

\subsubsection{Triple "c" Rule: Calming Down, Communication, and Counseling}

Psychologists believe that there is no comprehensive and universally agreed definition for aggression (as cited in Zirpoli, 2014). However, all of us agree that aggressive behaviors are aimed intentionally at ruining the image of a power figure who might be the cause of dissatisfaction. In fact, aggression is sometimes the only outlet an aggressor calls on. In any case, what is counterproductive and not recommendable is the instructors' immediate reaction towards aggressors (Linsin, 2010).

In the proactive model, the triple "c" component has been inspired by the triple p strategy that stands for positive parenting program in working out the emotional and behavioral problems of children (Queensland government, 2016). As a proactive de-escalating technique, the triple "c" builds on the advice of a group of psychology experts and educators (e.g., Gallagher, 2014; Kuhlenschmidt \& Layne, 1999; Makofsky, 2014; "Mindtools", 2015; Munson, 2012). 
The first component of the triple "c" is "calming down" as opposed to immediate decision making. This component encourages an instructor to give enough time and space to the aggressor or himself to reevaluate the situation and to adopt the best decision. That is to say, a brief time gap can be very instrumental in toning down the face-shattering behavior of the aggressor.

The second component of the model is "communication" with manifold applications and meanings. In fact, the term here includes both the communication of regulations to the aggressor by an instructor, and probing the cause of an aggressive behavior.

Finally, the third component is "counseling". Obviously, the immediate outcome of counseling is tension reduction. By raising awareness in learners about their talents and capabilities, the norms of an educational system, and the strategies of handling problems, they usually function better and achieve higher academically (Carey \& Dimmitt, 2012).

\section{Conclusion and Suggestion}

Change is not always equal to upward mobility for all people. In academic settings, however, it is the responsibility of an instructor to maximize learners' productivity and commitment and to reduce their negative reactions. Highlighting the two psychological concepts of reactance and proactance, the present article briefly dealt with a theoretical model, labeled as proactive, which can be applicable in educational settings. The model, which has been inspired by Fox (2011), introduces four major types of reactance-related behaviors, namely inertia, resistance, skepticism, and aggression. To tackle these four negative reactions, the model also offers four proactive antidotes of brainstorming, open conversation, small scale project assignment, and triple "c" rule. These strategies, if properly applied by instructors, can yield good results. In other words, the main results of the proactive model can be learners' self-awareness about their own weaknesses and potentials, stress and negativity reduction, and increase in their cognitive functioning. Of course, the aforementioned benefits are just theoretical opinions and yet no true empirical researches with experimental, and control groups have been conducted. Hence, due to the shortage of empirical literature in this regard, it could be a good investigation topic for researchers to assess the success of such proactive techniques in different cultural settings and in actual classroom management.

\section{References}

Allen, G. (2006). Is discrimination de-motivating? The case of black Caribbean boys and girls. Retrieved from http://www.leeds.ac.uk/educol/documents/157314.htm

Belcher, L. M. (2016). A list of strategies to decrease resistance to change in the workplace | Chron.com. Retrieved from http://smallbusiness.chron.com/list-strategies-decrease-resistance-change-workplace-20966.html

Bourion, C. (2005). Aversive situations: Challenge and self-doubt. Emotional Logic and Decision Making, 39-84. https://doi.org/10.1057/9780230508453_3

Brehm, J. W. (1966). A theory of psychological reactance. Academic Press.

Brehm, S., \& Brehm, J.W. (1981). Psychological reactance: a theory of freedom and control. New York: Academic Press.

Bylsma, L. M., Morris, B. H., \& Rottenberg, J. (2008). A meta-analysis of emotional reactivity in major depressive disorder. Clinical Psychology Review, 28(4), 676-691. https://doi.org/10.1016/j.cpr.2007.10.001

Carey, J., \& Dimmitt, C. (2012). School counseling and student outcomes: Summary of six statewide studies. Professional School Counseling, 16(2), 146-153. https://doi.org/10.5330/psc.n.2012-16.146

Chapman, A. (2006/2013). Elizabeth Kubler Ross grief cycle model, five stages of grief in death, dying and bereavement. Retrieved from http://www.businessballs.com/elisabeth_kubler_ross_five_stages_of_grief.htm

Clunies - Ross, P., Little, E., \& Kienhuis, M. (2008). Self - reported and actual use of proactive and reactive classroom management strategies and their relationship with teacher stress and student behavior. Educational Psychology, 28(6), 693-710. https://doi.org/10.1080/01443410802206700

Davis, J. R., \& Arend, B. (2013). Cultivating problem-solving and decision-making abilities. In Facilitating seven ways of learning: A resource for more purposeful, effective, and enjoyable college teaching (pp. 139-176). Sterling, VA: Stylus.

De las Cuevas, C., Peñate, W., Betancort, M., \& De Rivera, L. (2014). Psychological reactance in psychiatric 
patients: Examining the dimensionality and correlates of the Hong Psychological Reactance Scale in a large clinical sample. Personality and Individual Differences, 70, 85-91. https://doi.org/10.1016/j.paid.2014.06.027

Dowd, E.T., Wallbrown, F., Sanders, D., \& Yesenosky, J. M. (1994). Psychological reactance and its relationship to normal personality variables. Cognitive Therapy and Research, 18(6), 601-612. https://doi.org/10.1007/bf02355671

Fox, M. (2011). The 3 types of psychological resistance that cause you to lose sales - PersuasionTheory.com. Retrieved from https://frictionfreesales.com/3-types-psychological-resistance-cause-you-to-lose-sales/

Gentry, B. (2016). Insights - Coaching people through the change curve. Retrieved from https://www.insights.com/5930/coaching-people-through-the-change-curve.html

Grant, A. M., \& Ashford, S. J. (2008). The dynamics of proactivity at work. Research in Organizational Behavior, 28, 3-34. https://doi.org/10.1016/j.riob.2008.04.002

Grant, J., \& Leppink, E. W. (2015). Choosing a treatment for disruptive, impulse-control, and conduct disorders. Retrieved

from http://www.mdedge.com/currentpsychiatry/article/89627/adhd/choosing-treatment-disruptive-impulse-control-a nd-conduct

Haines-Gadd, L. (2016). Breaking the psychological inertia with the TRIZ creativity tools. In TRIZ for dummies: A Wiley brand (pp. 126-136). Chichester, West Sussex: John Wiley \& Sons, Ltd.

Hohlbaum, C. L. (2016). Our brains are wired for inattention and inertia | Psychology Today. Retrieved from https://www.psychologytoday.com/blog/the-power-slow/201609/our-brains-are-wired-inattention-and-inertia

Jost, J. T. (2015). Resistance to change: A social psychological perspective. Social research, 82(3), 607-636.

Kinder, C. (1987/2016). 87.05.03: The effects of institutions on human behavior. Retrieved from http://teachersinstitute.yale.edu/curriculum/units/1987/5/87.05.03.x.html

Klonek, F. E., Güntner, A. V., Lehmann-Willenbrock, N., \& Kauffeld, S. (2015). Using motivational interviewing to reduce threats in conversations about environmental behavior. Frontiers in Psychology, 6, 1-16. https://doi.org/10.3389/fpsyg.2015.01015

Kübler-Ross, E. (1969). On death and dying. NY: Macmillan.

Kuhlenschmidt, S. L., \& Layne, L. E. (1999). Strategies for dealing with difficult behavior. New Directions for Teaching and Learning, 1999(77), 45-57. https://doi.org/10.1002/tl.7705

Kuppens, P., Allen, N. B., \& Sheeber, L. B. (2010). Emotional inertia and psychological maladjustment. Psychological Science, 21(7), 984-991. https://doi.org/10.1177/0956797610372634

Linsin, M. (2010). How to handle an angry, verbally aggressive student. Retrieved from http://www.smartclassroommanagement.com/2010/05/08/how-to-handle-an-angry-verbally-aggressive-student/

Makofsky, N. (2014). How to manage violent \& aggressive children in school | LIVESTRONG.COM. Retrieved from http://www.livestrong.com/article/232102-how-to-manage-violent-aggressive-children-in-school/

Mazurkiewicz, A. (2015). Proactivity in shaping young people's career. Social Sciences, 89(3). https://doi.org/10.5755/j01.ss.89.3.13672

Mindtools. (2016). Dealing with angry people - Communication skills from MindTools.com. Retrieved from https://www.mindtools.com/pages/article/dealing-with-angry-people.htm

Miner, A. S., Schueller, S. M., Lattie, E. G., \& Mohr, D. C. (2015). Creation and validation of the cognitive and behavioral response to stress scale in a depression trial. Psychiatry Research, 230(3), 819-825. https://doi.org/10.1016/j.psychres.2015.10.033

Moss, S. (2016). Psychological reactance theory / smoss2- Sicotests. Retrieved from http://www.sicotests.com/psyarticle.asp?id $=65$

Munson, J. S. (2012). Tips to help stop aggressive behavior in young children | How to learn.com. Retrieved from http://www.howtolearn.com/2012/05/tips-to-help-stop-aggressive-behavior-in-young-children/

Olfert, C. M. (2015). Skeptical investigation and its perks. In K. M. Vogt (Ed.), Pyrrhonian skepticism in Diogenes Laertius (pp. 147-162). Tübingen: Mohr Siebeck.

Parker, S. K., \& Collins, C. G. (2010). Taking stock: Integrating and differentiating multiple proactive behaviors. 
Journal of Management, 36(3), 633-662. http://dx.doi.org/10.1177/0149206308321554

Portier, C. (2016). Change curve: 4 stages of change management acceptance. Retrieved from

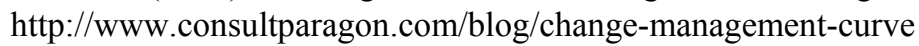

Pro- | Define Pro- at Dictionary.com. (2016). Retrieved from http://www.dictionary.com/browse/pro-

Queensland government. (2016). Triple P - Positive parenting program | Community support | Queensland Government. Retrieved from https:/www.qld.gov.au/community/caring-child/positive-parenting/

Quick, B. L., \& Stephenson, M. T. (2008). Examining the role of trait reactance and sensation seeking on perceived threat, state reactance, and reactance restoration. Human Communication Research, 34(3), 448-476. https://doi.org/10.1111/j.1468-2958.2008.00328.x

Reynolds, G. (2015). Knowledge management. In information technology for managers (pp. 286-300). Boston: Cengage Learning.

Rick, T. (2013). Change is not the problem - resistance to change is the problem. Retrieved from https://www.torbenrick.eu/blog/change-management/change-is-not-the-problem-resistance-to-change-is-the-pro blem/

Sharp, S. (2011). Workshop to help your student. In a new look at the interactive writing classroom: Methods, strategies, and activities to engage students (pp. 136-146). Lanham, MD: Rowman \& Littlefield Education.

Sherman, D. K., \& Cohen, G. L. (2006). The Psychology of self - defense: Self - affirmation theory. Advances in Experimental Social Psychology, 38, 183-242. https://doi.org/10.1016/S0065-2601(06)38004-5

Webster, M. (2016). 10 steps to manage psychological resistance to change $\bullet$ Leadership thoughts blog. Retrieved from http://www.leadershipthoughts.com/10-steps-to-manage-psychological-resistance-to-change/

Wright, T., Eberhard, J., Hobson, E., Avery, M., \& Russello, M. (2010). Behavioral flexibility and species invasions: the adaptive flexibility hypothesis. Ethology Ecology \& Evolution, 22(4), 393-404. https://doi.org/10.1080/03949370.2010.505580

Zhang, Q., \& Sapp, D. A. (2013). Psychological reactance and resistance intention in the classroom: Effects of perceived request politeness and legitimacy, relationship distance, and teacher credibility. Communication Education, 62(1), 1-25. https://doi.org/10.1080/03634523.2012.727008

Zirpoli, T. J. (2014). Aggressive behavior | Education.com. Retrieved from http://www.education.com/reference/article/aggressive-behavior/

\section{Notes}

Note 1. The change curve image has been retrieved from http://www.eljamal.com/wiki_generation/

Note 2. The diagram has been developed by the author based on Fox's explanations (2011).

Note 3. The diagram has been developed by the author based on Parker and Collin's explanations (2010). 